\title{
Justification of the design of pneumatic sorting machine for the preparation of selection seeds
}

\author{
Viktor Khamyev ${ }^{1, *}$, Anatoly Gulyev ${ }^{1}$, and Andrey Boiko² \\ ${ }^{1}$ Federal Scientific Agroengineering Center VIM, 1-st Institutsky proezd, 5, Moscow, 109428, Russia. \\ ${ }^{2}$ Don State Technical University, Gagarin Square, 1, Rostov-on-Don, 344000, Russia.
}

\begin{abstract}
The results of the study of the determination of the optimal parameters of the narrowing partitions installed in pneumatic channels with a vertical ascending air flow, intended for seed cleaning, are presented. The installation of the narrowing walls in the pneumatic channels makes it possible to increase the productivity and efficiency of seed cleaning from hardly separated impurities at least $20 \%$, while the optimal ratio of the width of the partitions and the depth of the sections of the air channel varies from 0.3 to 0.5 .
\end{abstract}

\section{Introduction}

There is necessary 10 years for the breeding of a new sort, from the collection nursery to the final introduction into production. Reduction of this period and increasing in experimental plots are impossible without the development and introduction into production of highly efficient machines that mechanize all work in the selection process.

The principle of air separation of particles with various aerodynamic properties has long been used in many separating devices, especially in machines for cleaning seeds. This is explained by the comparative simplicity of both the separation technology and the compactness of the structures of the air-separating devices. The most widely using method is the separation of seeds in a vertical-rising air flow. However, these pneumatic separating devices have some drawbacks. For example, the cleaning efficiency depends on its depth in pneumatic channels of a rectangular shape. We saw increasing of efficiency with increasing depth of the channel to a certain level, and then We saw decreasing of efficiency. Thus, with a specific load per $100 \mathrm{~kg} /(\mathrm{cm} \cdot \mathrm{h})$, the maximum cleaning efficiency $(75 \%)$ is achieved at a depth of $260 \ldots 270 \mathrm{~mm}$. This is due to the fact that as the depth of the channel increases, the nonuniformity of the airflow velocity distribution increases, which is why the efficiency of the separation process decreases.

For increasing the efficiency of the process, the specific grain load is reduced by increasing the width of the channel, which becomes, as a rule, many times greater than its depth. However, in this case, high efficiency of separation $(85 \ldots 95 \%)$ of grain material is achieved only at small specific (per unit area of the channel section) loads - up to $1 \mathrm{~kg} /$ $\left(\mathrm{dm}^{2} \cdot \mathrm{h}\right)$, which are significantly lower than loads in other machines used [1] .

\footnotetext{
* Corresponding author: victor250476@yandex.ru
} 
Increasing the efficiency of the separation process in the pneumatic channel is possible due to the installation of specially designed devices (narrowing partitions) that stabilize the uniformity of airflow velocity distribution along the channel depth and thus ensure the possibility of using deep channels $[2,6]$.

The aim of the study is to justification the design parameters of a pneumatic separating channel with narrowing partitions for highly efficiency selection seed separation.

\section{Materials and methods}

The studies were carried out on a experimental installation of a seed cleaning plant (Figure. 1). The installation contains a pneumatic channel of rectangular cross-section with a width of $80 \mathrm{~mm}$ and a depth of $450 \mathrm{~mm}$.

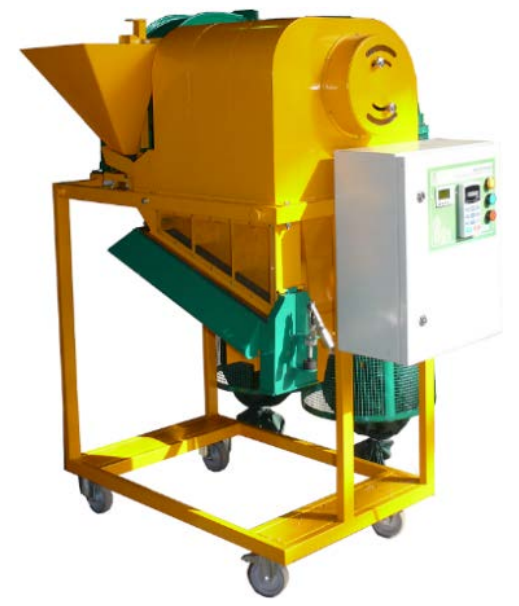

Fig. 1. View of the prototype of a plant for cleaning seeds.

On the figure. 2. It is showed the constructive scheme of the pneumatic channel, where 1 - channel frame, 2 - supporting grid, 3, 4 - windows for receiving the initial and output of the cleaned seed material, 5 - narrowing partitions, 6 - channel sections.

Pneumatic channel are operated in such way. Raw material (seeds and impurities) are put in input window (3) into channel, where exposed to an ascending airflow, sucked from above by an airflow generator (not shown).

As a result of the influence of the ascending air stream, the grain material acquires the state of a "boiling" layer, which moves from the front wall of the channel to the back, splitting into fractions. Particles of light fraction (impurity) float to the upper layers of the grain flow. The heavier particles (seeds) stay in the lower layers of the flow of the processed material over the supporting mesh 2 , touching it to some extent, depending on the speed of the air flow. The velocity of the air flow above the " boiling " layer is not sufficient to allow some light fraction particles to be taken out of the air channel. Narrowing partitions 5 are provided for reducing the cross-sectional square of the air channel, increasing the speed of the air flow over the "boiling" layer and creating conditions for the removal of light fraction particles through the baffle sections 6. Depending on the thickness of the layer of the material being processed along the supporting grid 2 from the window 3 to the window 4 , the clearance $(h)$ is adjusted by moving up or down the partitions 5 as a whole. 


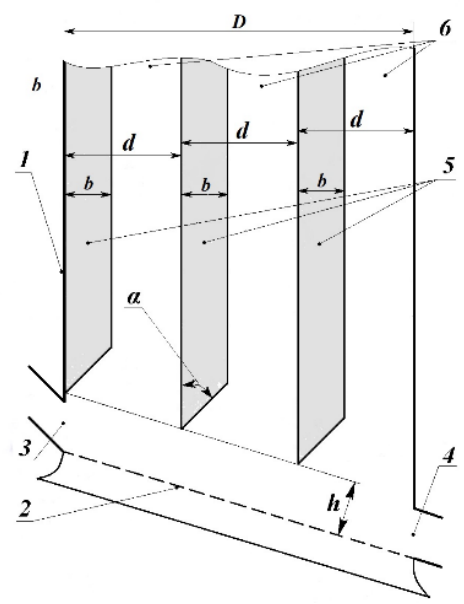

Fig. 2. Constructive scheme of a pneumatic channel of a experimental sample of a plant for cleaning seeds.

We justified such results in the experiments:

1. The optimum ratio of the width $b$ of the constriction partitions and the depth $d=150$ $\mathrm{mm}$ of the channel section (b/d), the specific grain loading in the channel being $3 \mathrm{~kg} /$ $(\mathrm{cm} 2 \mathrm{~h}$ ), the width of the partitions : 0 (without partitions) 45, 70, 90, 95 and $120 \mathrm{~mm}$, and the angle $\alpha$ of the partition (Figure 2) took an arbitrary equal to 50 degrees. The amount of the main component in the waste was not more than $10 \%$ in this experiment.[3,4,5].

2 Optimal angle $\alpha$ of the partition (Figure 2) for different specific grain loads, $\alpha$ being taken as 0 (without partitions), 30, 45 and 60 degrees.

After justifying the main parameters of the narrowing partitions, comparative studies were carried out to determine the completeness of the weed separation at various specific grain loads at the facilities: the Petkus air separator K-293, a pneumatic channel without partitions and with baffles installed at a height h (Fig.2) of 50 and $70 \mathrm{~mm}$.

The plants were filled with a hard-to-separate two-component grain mixture with a moisture content of $11.4 \%$, consisting of wheat seeds (main material) and oats (at-mix) in an amount of 165 pieces per $1 \mathrm{~kg}$. The efficiency of material separation was evaluated through the completeness of the isolation of the $\varepsilon$ weed (oats) and the loss of the $\xi$ main component (wheat). The experiments were carried out in triplicate repetition, the relative error of the sample mean (accuracy of the experiments) was less than $5 \%$ with a confidence probability of 0.9 .

\section{Results and discussions}

It was presented graph of the completeness of the oat grain separation $\varepsilon$ from the ratio of the width of the baffle $b$ and the depth of the section $d$ of the pneumatic separating channel (Figure 3). It can be seen from the graph that the optimal b/d ratio varies from 0.3 to 0.5 , with the completeness of the separation between 80 and $90 \%$. 


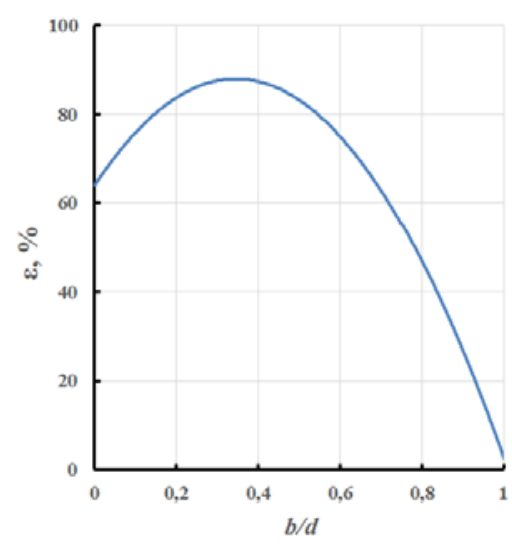

Fig. 3. Graph of the dependence of the completeness of oat grain allocation $\varepsilon$ on the ratio of the width of the constricted partitions $b$ and the depth of the section $d$ of the air separation channel.

It was presented graphs of the dependence of the completeness of the emission of $\varepsilon$ oats and the losses of wheat seeds on the specific grain load at different angles $\alpha$ of the constricted baffles (Figures 4,5). In this experiment, the width b of the septum was $90 \mathrm{~mm}$. It can be seen from the graphs that the optimal angle $\alpha$ of the partition is 45 degrees, with admissible losses up to $10 \%$ [].

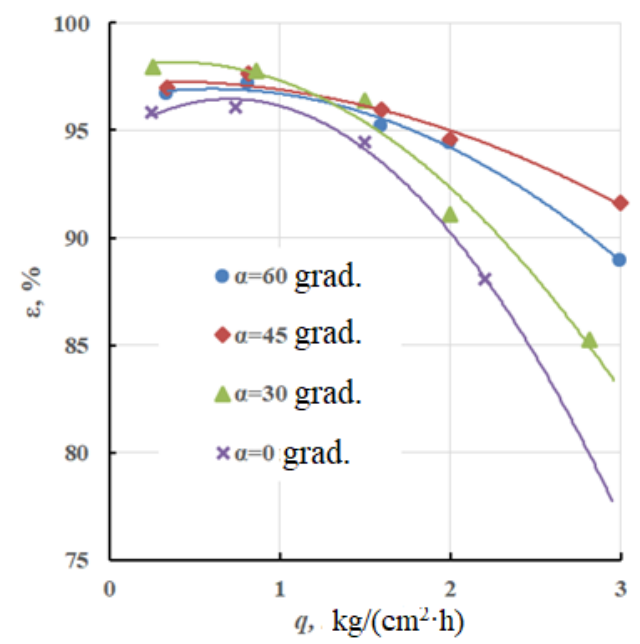

Fig. 4. Graph of the dependence of the completeness of the oat grain allocation $\varepsilon$ on the specific grain load of the initial material $\mathrm{q} . \mathrm{kg} /\left(\mathrm{cm}^{2} \cdot \mathrm{h}\right)$ 


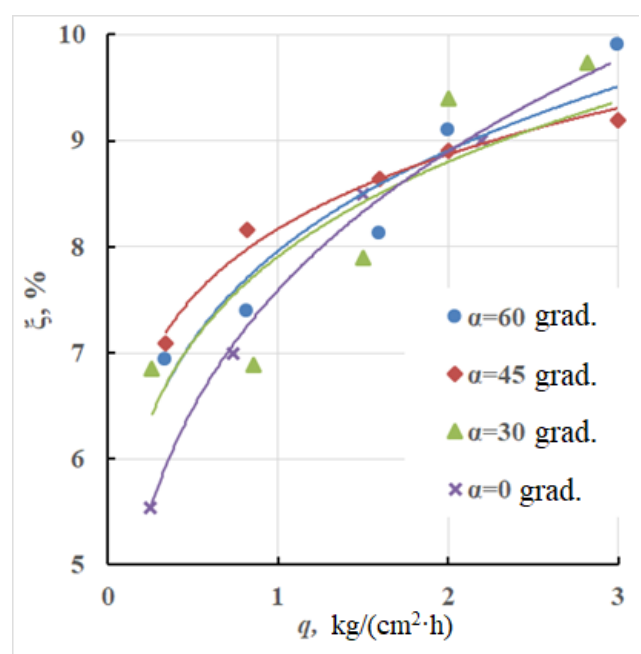

Fig. 5. The graph of the dependence of losses of wheat seeds $\xi$ in wastes from the specific grain load of the initial material q.

It was presented results of comparative studies, which showed that the installation in the pneumatic channel of the narrowing partitions increases the completeness of the emission of waste impurities. So, at a specific grain load of $2.5 \mathrm{~kg} /(\mathrm{cm} 2 \cdot \mathrm{h})$, the maximum total isolation $\varepsilon=96.7 \%$ at the channel with the partition installed at a height of $\mathrm{h}=50 \mathrm{~mm}$ (Figures 6).. If we compare by the specific grain loads, then for the fullness of the release, $\varepsilon$ $=98.0 \%$ in the air channel with the partition $(\mathrm{h}=50) \mathrm{q}=1.88 \mathrm{~kg} /(\mathrm{cm} 2 \cdot \mathrm{h})$, and in the K293 pneumatic channel Petkus $\mathrm{q}=1,25 \mathrm{~kg} /(\mathrm{cm} 2 \cdot \mathrm{h})$ and taking into account the crosssectional areas of the compared canals (in K-293 $25 \mathrm{~cm} 2$, and in the experimental sample of the installation $360 \mathrm{~cm} 2$ ), the production capacity of the pneumatic channel of the pilot plant $(677 \mathrm{~kg} / \mathrm{h})$ is greater than the productivity K-293 $(62.5 \mathrm{~kg} / \mathrm{h})$ in 10 times.

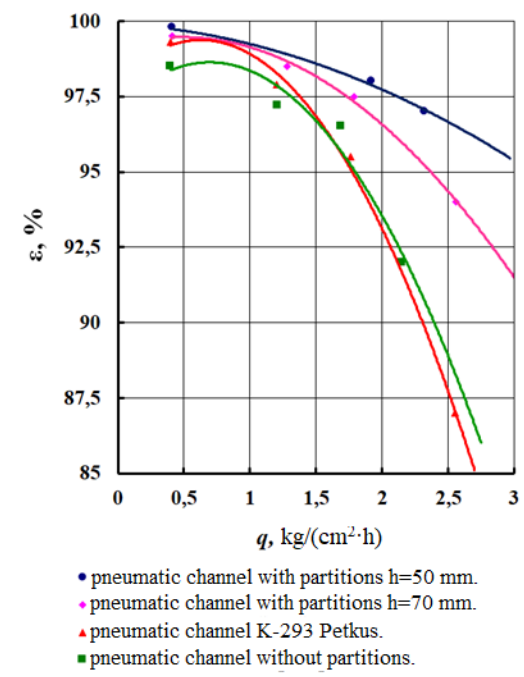

Fig. 6. Graph of the dependence of the completeness of the oat grain allocation $\varepsilon$ on the specific grain load of the initial material q. 


\section{Conclusions}

The installation of narrowing partitions in pneumatic channels with a vertically rising airflow makes it possible to increase the productivity and efficiency of cleaning seeds from hardly separable impurities by at least $20 \%$, while the optimum ratio of the width of the partitions and the depth of the sections of the air channel varies from 0.3 to 0.5 .

\section{Reference}

1. Pekhalsky I.A., Moskovskiy M.N., Reduction of seed injury by sieves, Rural mechanizer, 9, pp. 22-23. (2015)

3. Moskovskiy M.N., Synthesis of system solutions for the technological process of obtaining seeds on the basis of structural-functional modeling, Diss. doc. tech. sciences: ,Krasnodar, 491 p. (2017)

4. Moskovsky, M.N., Chumak, I.V., Chaava, M.M., Development of a structuralfunctional model of a single production process obtaining seed material in farms, ARPN Journal of Engineering and Applied Sciences, 13(6), pp. 6414-6418. (2018)

5. Adler Yu. P., Planning an experiment in the search for optimal conditions, Science, 280 p. (1976)

6. Paulsen M. R., Nave W. R., Corn damage from conventional and rotary combines, Transactions of the ASABE.23 (5):

1100_1116. @1980:URL:elibrary.asabe.org/abstract.asp?search=1\&JID=3\&AID=347 $29 \& \overline{\mathrm{C} I D}=\mathrm{t} 1980 \& \mathrm{v}=23 \& \mathrm{i}=5 \& \mathrm{~T}=1 \&$ urlRedirect $=$ [anywhere $=$ on\&keyword $=\&$ abstract $=$ $\&$ title $=\&$ author $=\&$ references $=\&$ docnumber $=\&$ journals $=$ All $\&$ searchstring $=\& p g=\&$ allw ords $=$ grain $\% 20$ near $\% 20$ clean $\&$ exactphrase $=\&$ OneWord $=\&$ Action $=$ Go\&Post $=Y \& q u=]$ \&redirType $=$ newresults.asp 